NATURE INDEX | COLLABORATIONS

\title{
SCIENCE SUPERPOWERS FIND COMMON GROUND
}

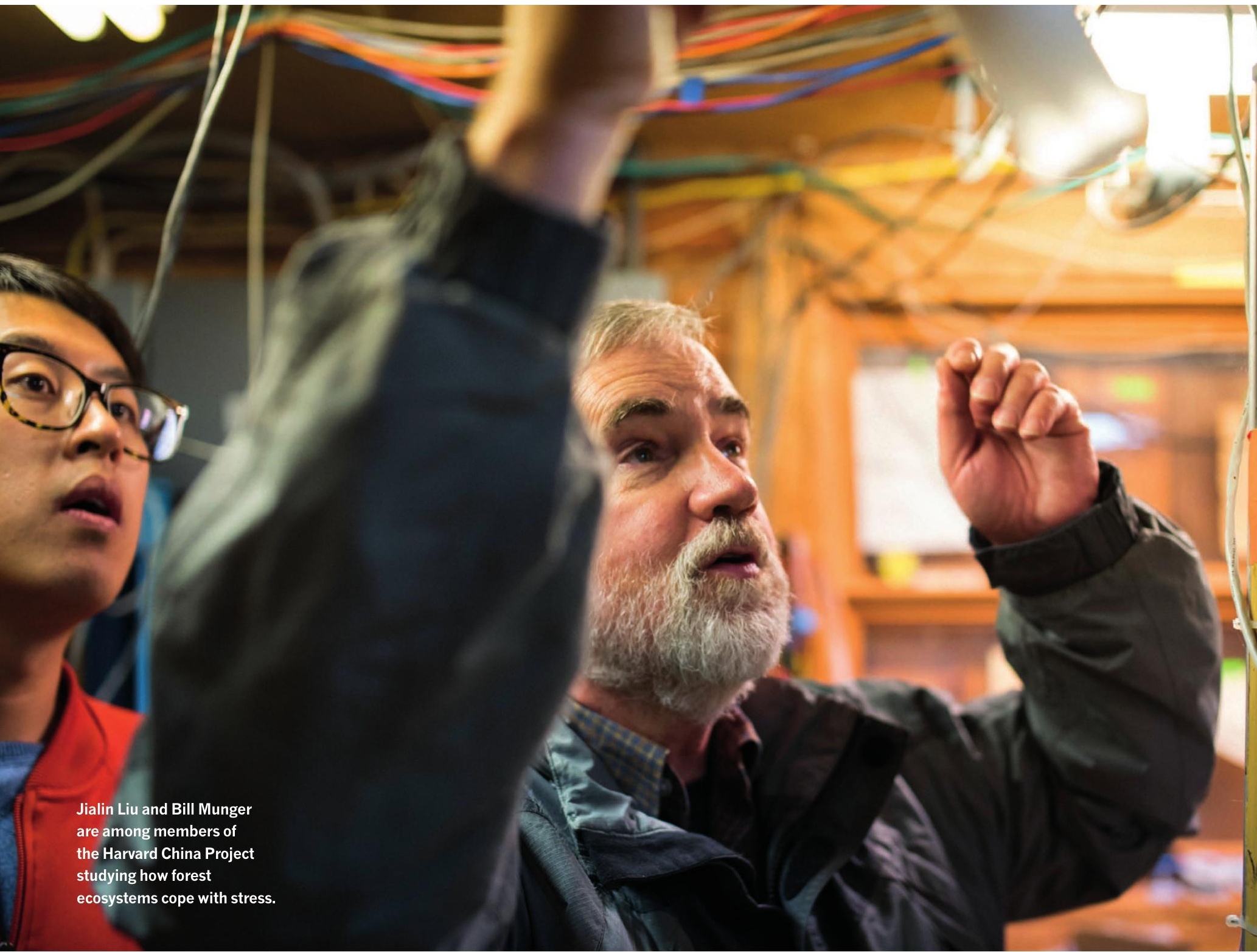




\title{
Chinese-US research partnerships outnumber all other international pairings. That trend, spurred by a long history of collaboration between the two countries, presents challenges, but the outcomes are a major boon for science.
}

\author{
BY SUJATA GUPTA
}

I n 2014, Lei Zhao, a Chinese student completing his doctorate at Yale University in New Haven, Connecticut, developed a model to clarify the causes of the heat-island effect. Such heat islands, or regional pockets of warm air, occur due to human activity and tend to be most pronounced in urban areas.

"Generally speaking, in a large city, you have a stronger heat island," says Xuhui Lee, a climate scientist at Yale who oversaw the project.

Zhao calculated the average temperature difference between the downtown and outskirts of 65 cities across the United States and Canada. Despite some anomalies, his model confirmed the principle that the urban heatisland effect intensifies as tree cover and vegetation diminishes. As expected, bigger cities generally had more acute heat islands.

Zhao's team then decided to test the model in China by applying it to 40 medium to large cities and found that the heat-island effect was stronger in smaller, midwestern cities than megalopolises like Shanghai and Beijing. The team wondered what was going on.

The goal of any climate modeller, says Lee, is to develop a program that will work anywhere in the world. But, were it not for Yale's collaborative program with China, known as the YaleNUIST (Nanjing University of Information Science \& Technology) Center on Atmospheric Environment, the shortcomings of Zhao's models would never have been discovered.

International research collaborations are on the rise. In $2013,19.2 \%$ of research papers included authors from more than one country, up from $13.2 \%$ in 2000 , according to the National Science Foundation's Science and Engineering Indicators 2016. This increase is probably due to improvements in communications technology, a growing number of qualified researchers, and problems, such as climate change and food insecurity, that need global solutions.
Partnerships between the largest producers of publications, the US and China, are particularly prolific. Analysis of 68 high-quality natural science journals included in the Nature Index shows Chinese and American researchers have collaborated in top journals more than other international pairings. In the last four years, Chinese-American partnerships in the physical and life sciences have more than doubled.

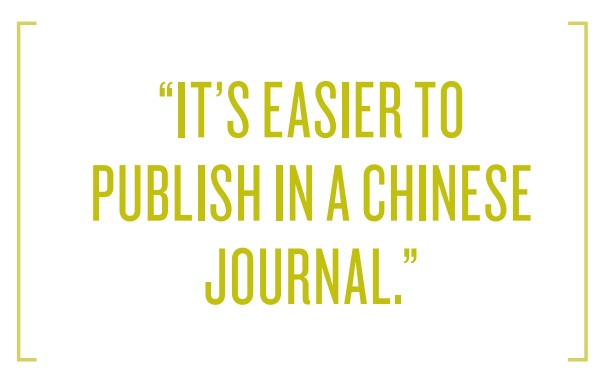

The research relationship between China and the US has a long history, says Richard Suttmeier, an expert on Chinese science policy and professor emeritus at Oregon State University in Eugene. Suttmeier has conducted several studies of papers with Chinese and American authors to determine the authors' identities. He found that many partnerships were between the large diaspora of Chinese researchers in the US and their compatriots in China - a phenomenon he refers to as "coethnic cooperation", and to which he attributes China's stronger links with the US than with other English-speaking countries.

Almost a quarter of close to 400,000 foreignborn holders of a science or engineering doctorate in the US come from China, according to the National Science Foundation's Science and Engineering Indicators 2016.
Chinese graduate students began coming to study in the US in the 1940s, but the modernday relationship began in the late 1970s. The Cultural Revolution, which effectively froze scholarly activity for a decade, ended with the death of Mao Zedong in 1976. The leader's successor, Deng Xiaoping began opening China's markets and accelerating the pace of scientific research. In 1979, Xiaoping and US President Jimmy Carter signed the landmark US-China Science and Technology Cooperation Agreement, setting the stage for longterm collaboration.

Political tensions between the two countries had stemmed the flow of students from China to the US in the previous decades, but the two leaders signed an agreement on the exchange of students and scholars, reopening the path for Chinese students to study in the US. Today, graduates from China in the US outnumber all other nationalities, comprising more than $30 \%$ of the US's foreign student population.

Since 1979, the Chinese government has continued its push to become a world leader in research and development. In just the last four years funding for the National Natural Science Foundation of China, the country's equivalent to the US National Science Foundation, has quadrupled. Chinese faculty are encouraged to study and conduct research overseas to gain the skills and experience of world-class scientists. Chinese researchers also report intense pressure to publish in English language journals. "It's much easier to publish in a normal Chinese journal but I don't want to invest a lot of time on that," says Wei Xiao, China-based co-director of the Yale-NUIST center. "If you want to be a research professor, you have to publish in a good English journal."

Collaborating with international partners also increases access to funding, say Lee and others. That can be beneficial for US-based researchers, where competition is increasing 


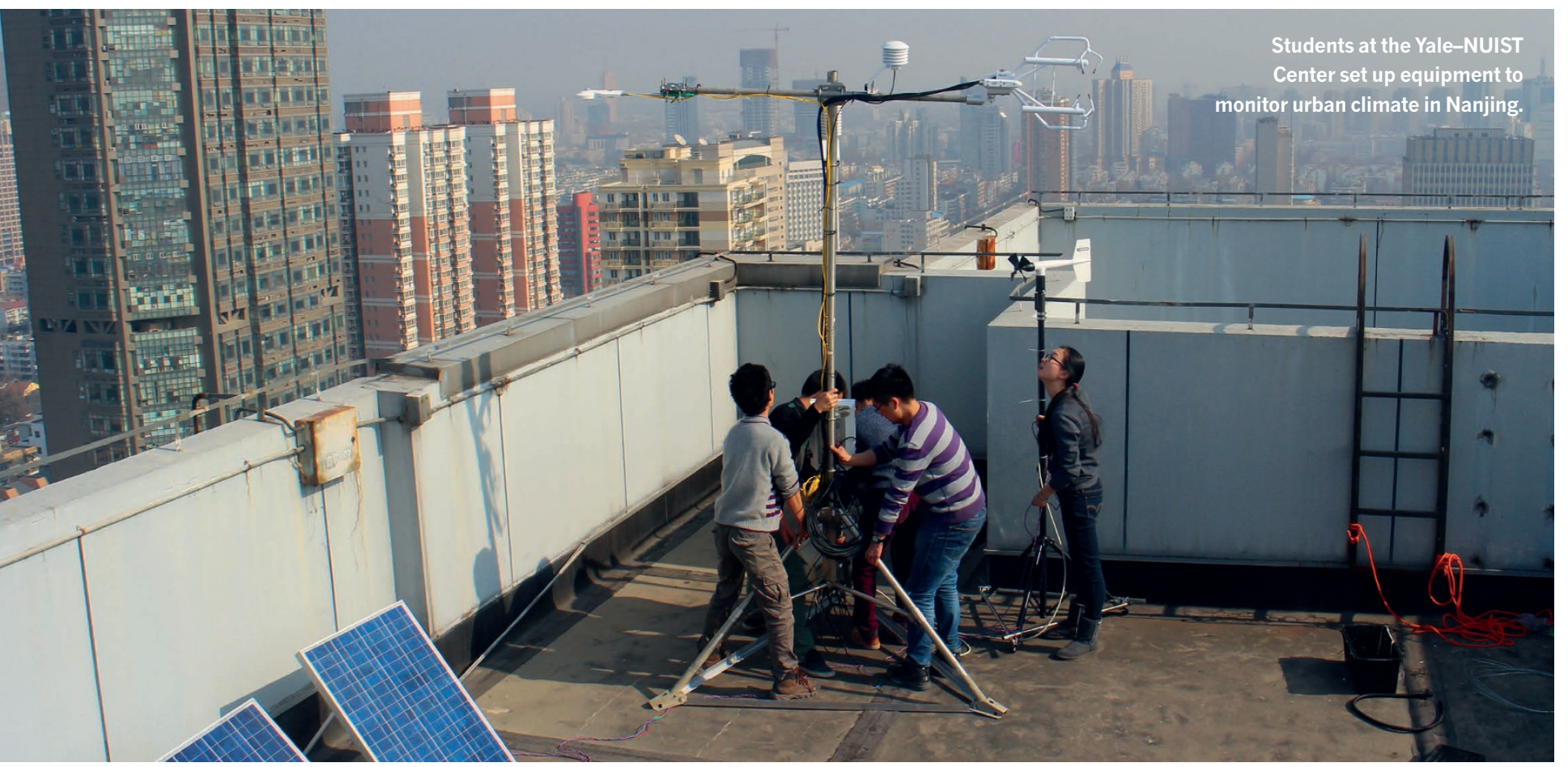

and research dollars are shrinking. A researcher applying for NSF funding has only about a one in four chance of landing a grant.

"We have to leave some good proposals because we don't have funding," says Rebecca Keiser, head of NSF's International Office of Science and Engineering in Arlington, Virginia. Some US researchers have been looking to tap into China's growing pot of research money. By putting the Yale-NUIST centre in China, for instance, Chinese researchers involved with the programme can apply for funding in China and share it with their US counterparts. "It's difficult to get funding for large field programmes in the US. But in China, you can get a large grant," Lee says.

Chinese researchers also have more money for technological instruments as they can receive funding through institutional, regional, and federal agencies. In the US, by comparison,

"SOMETIMES THEY ARE TOO EAGER, AND THE DEPTH OF RESEARCH IS INSUFFICIENT", says Tim Griffis, a biometeorologist at the University of Minnesota in St. Paul who often collaborates with Chinese researchers, US researchers typically receive funding for new instruments only when they change universities and have to set up a new lab.

Griffis recalls visiting labs in Nanjing and Beijing in 2012. "They had all the latest toys and analysers. In some labs, they didn't even have space to set them up and had to put them in the hallways," he says.

\section{CULTURAL CHALLENGES}

The research alliance has created a brain drain for China, with considerably more Chinese students studying and even settling in the US than vice versa. Since 2008, China has sought to compensate by proactively luring talented foreign, often ethnic Chinese, scientists living overseas back through the Thousand Talents Plan. Despite China's desire to lure top scientists, they face formidable challenges, Suttmeier says. Few scientists in the US or elsewhere speak Chinese or understand the country's research culture. Many worry about China's environmental problems and the Chinese government's control over the internet. "China, on the one hand, would like to become a magnet for foreign scientists. In recent policy documents, they even talk in those terms," Suttmeier says. "But cultural barriers prevent them from becoming the truly cosmopolitan environment they would like to have."

There are also challenges with disparate research cultures. Bin Wang, a climate scientist at the University of Hawaii, says he often has to encourage Chinese graduate students and visiting scholars to focus on quality over quantity. "They very much want to write scientific papers but sometimes they are too eager and the depth of the research, is insufficient," he says. Wang says that when faculty and students return to China they begin to apply the same rigorous standards in their own labs, which strengthens international collaboration. The gains are indisputable.

The Yale-NUIST research into the urban heat island effect is a case in point. After Zhao completed his doctorate, he was replaced by Chang Cao, a doctoral student in Yale-NUIST's joint $\mathrm{PhD}$ programme. After her arrival, says Cao, the Yale team tested the model on China and soon determined that it did not account for haze, or particulate matter suspended in the air. Haze is particularly problematic in Chinese cities reliant on coal, whose soot particles released by burning radiate energy down towards the Earth.

Lee says creating the urban heat island model would not have been possible without his Chinese collaborators, in terms of money and manpower. The haze study, published in Nature Communications this year, was funded by Chinese backers, including the National Natural Science Foundation of China, the Ministry of Education of China, and the China Scholarship Council, which funds the Yale-NUIST joint $\mathrm{PhD}$ programme that enabled Cao and Zhao to come to the US. Lee says, "we could not have carried out the work without Cao."

Cao is now back in China and another Chinese graduate student has taken her place. But, Cao hopes to return to the US when she completes her doctorate in 2017. "I want to find a post-doc if there are chances," she says. 


\section{CHINA AND US RELATIONS}

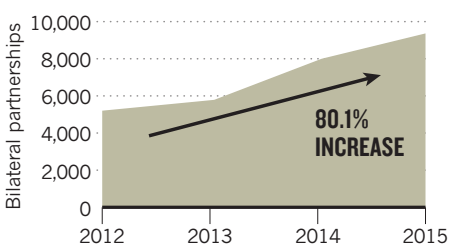

A bilateral partnership is between one US and one Chinese institution.

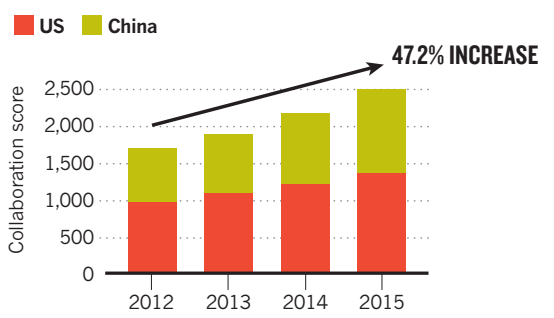

Collaboration score measures the output of US-Chinese partnerships in the index. While the number of

partnerships (above) has almost doubled, the output of those collaborations has not increased at the same pace.

\section{TOP 10 US-CHINA PARTNERSHIPS}

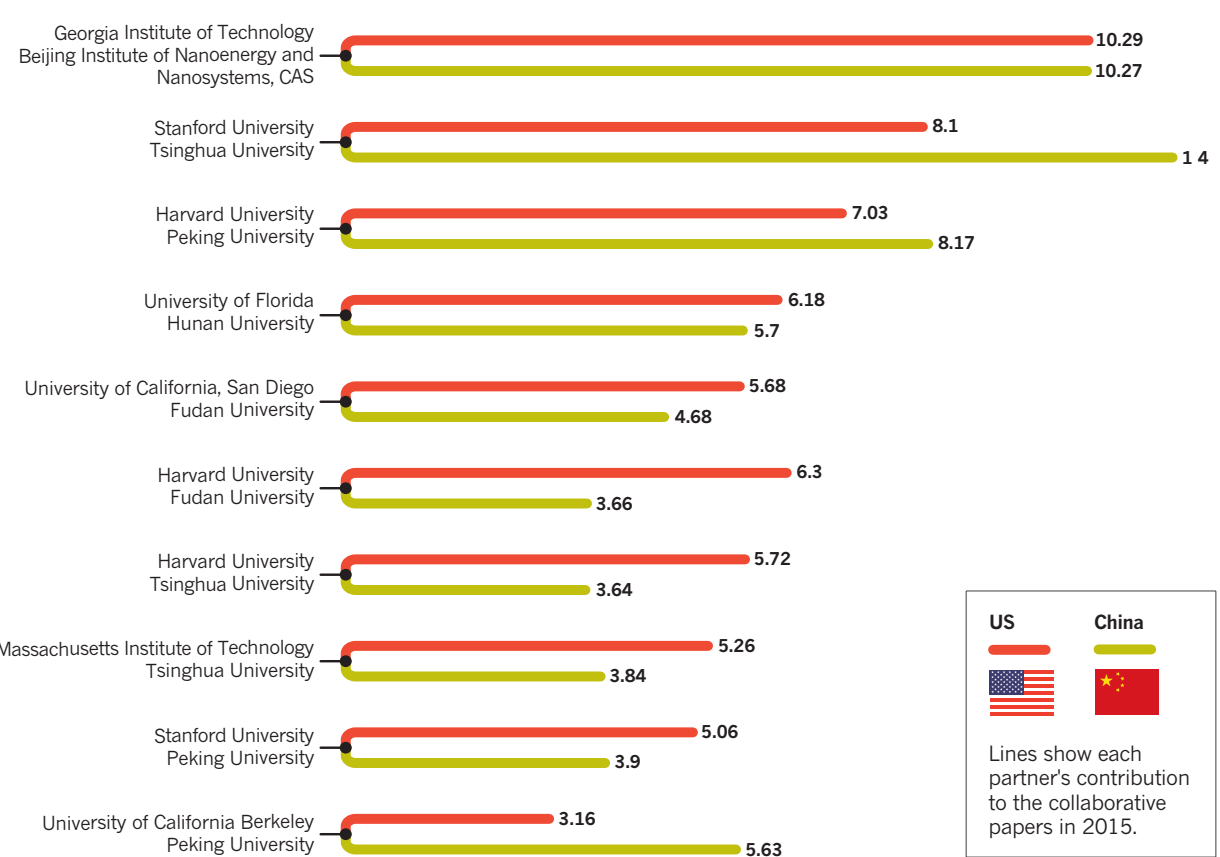

\section{CLIMATE AT THE FOREFRONT}

There's an obvious reason for universities in China and the US to collaborate on climate change research. "The largest contributor to greenhouse gases is China, the second is the US," says Michael McElroy, an atmospheric scientist at Harvard University in Cambridge, Massachusetts.

Addressing climate change, says McElroy, "is a very broadly based common challenge" for both countries. McElroy realized the need to work with partners in China to study the problem back in the early 1990s when he established the Harvard China Project, the first university-wide programme aimed at fostering partnerships focused on climate change.

The programme now includes around 25 researchers from both countries and involves partnerships between Harvard and leading Chinese institutions, including Tsinghua, Nanjing, and Peking universities. Index analysis shows that Harvard's links with these universities represent some of the most productive collaborations between
China and the US (see graphic). Over the years, project researchers have published studies in numerous top-tier journals.

One of the project's new collaborative endeavors is to understand how forest ecosystems respond to stress by developing models based on observational sites in China and the US. "Forests are generally absorbing carbon from the atmosphere, but that would stop if they were damaged by climate change or pollution," says the project leader from Harvard, Bill Munger.

In October, PhD student Jialin Liu, from Northeast Forestry University in China, started working with Munger, and another PhD student Archana Dayalu, at the observation site in the Harvard Forest, Massachusetts. The goal of his project is to share expertise that can help Liu analyze his data and get his work published.

Liu hopes his year-long stint in the US will open further opportunities and collaborations. "The academic atmosphere in the US is very open," he says. .

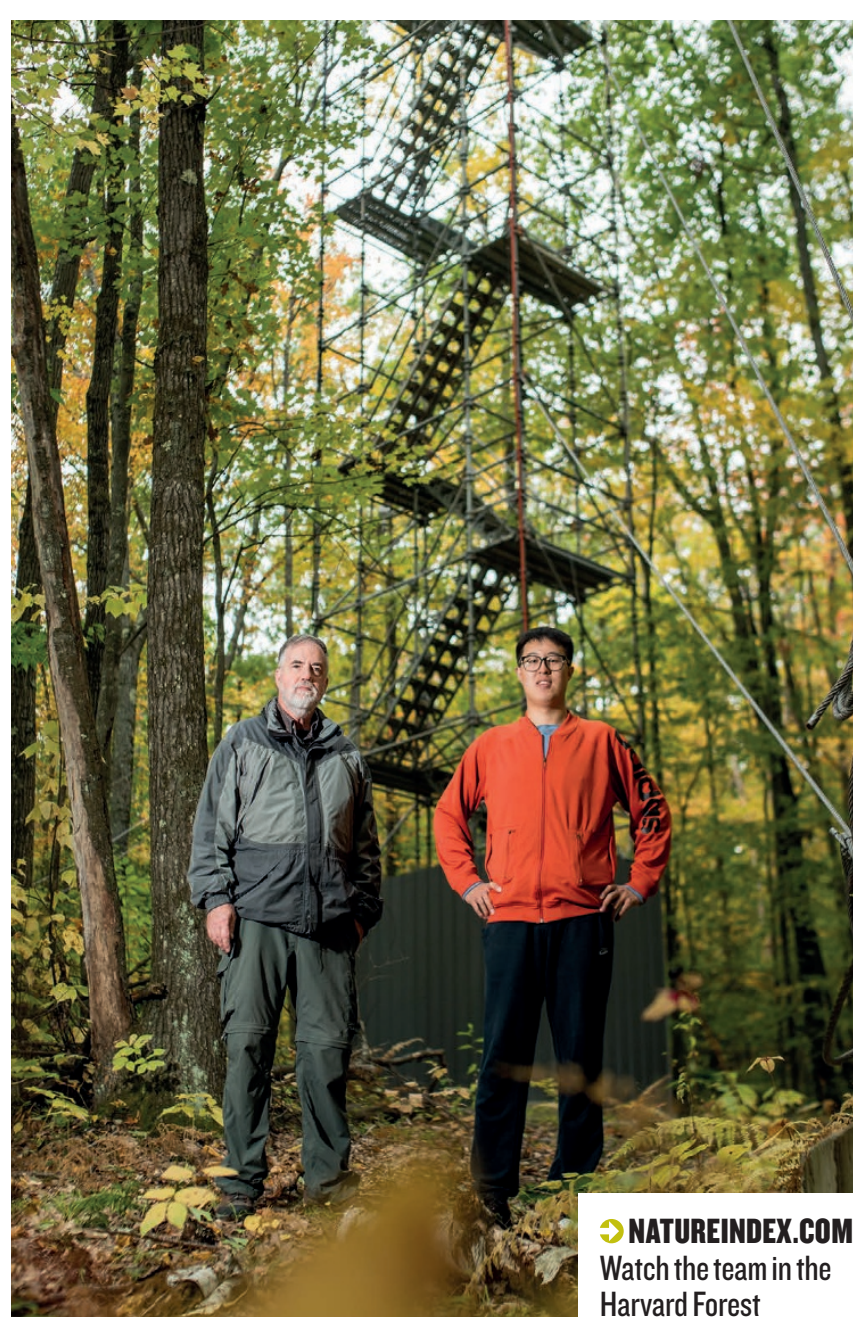

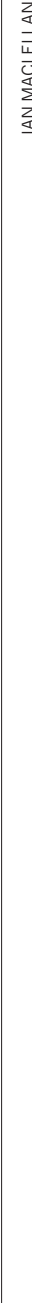

